\title{
Lack of Association of Initial Viral Load in SARS-CoV-2 Patients with In-Hospital Mortality
}

Anna Carrasquer, ${ }^{1,2,3}$ Óscar M. Peiró, ${ }^{1,2,3}$ Raul Sanchez-Gimenez, ${ }^{1,2,3}$ Nisha Lal-Trehan, ${ }^{1,2,3}$ Victor del-Moral-Ronda, ${ }^{1,2,3}$ Gil Bonet, ${ }^{1,2,3}$ Cristina Gutierrez, ${ }^{4}$ Isabel Fort-Gallifa, ${ }^{4}$ Carla Martin-Grau, ${ }^{4}$ Clara Benavent, ${ }^{4}$ Francesc Vidal, ${ }^{2,3,5}$ and Alfredo Bardaji $i^{1,2,3 *}$

${ }^{1}$ Department of Cardiology, Joan XXIII University Hospital, Tarragona, Spain; ${ }^{2}$ Pere Virgili Health Research Institute (IISPV), Tarragona, Spain; ${ }^{3}$ Rovira i Virgili University, Tarragona, Spain; ${ }^{4}$ Clinical Laboratory, Catalan Institute of HealthTarragona, Spain; ${ }^{5}$ Infectious Disease Unit, Department of Internal Medicine, Joan XXIII University Hospital, Tarragona, Spain

\begin{abstract}
Controversy exists in the literature regarding the possible prognostic implications of the nasopharyngeal SARS-CoV-2 viral load. We carried out a retrospective observational study of 169 patients, $96(58.9 \%)$ of whom had a high viral load and the remaining had a low viral load. Compared with patients with a low viral load, patients with a high viral load did not exhibit differences regarding preexisting cardiovascular risk factors or comorbidities. There were no differences in symptoms, vital signs, or laboratory tests in either group, except for the maximum cardiac troponin I (cTnl), which was higher in the group with a higher viral load (24 [interquartile range 9.5-58.5] versus 8.5 [interquartile range 3-22.5] ng/L, $P=$ 0.007). There were no differences in the need for hospital admission, admission to the intensive care unit, or the need for mechanical ventilation in clinical management. In-hospital mortality was greater in patients who had a higher viral load than in those with low viral load (24\% versus $10.4 \%, P=0.029)$. High viral loads were associated with in-hospital mortality in the binary logistic regression analysis (odds ratio: $2.701,95 \%$ Charlson Index (Cl): 1.084-6.725, $P=0.033$ ). However, in an analysis adjusted for age, gender, $\mathrm{Cl}$, and $\mathrm{cTn}$, viral load was no longer a predictor of mortality. In conclusion, an elevated nasopharyngeal viral load was not a determinant of in-hospital mortality in patients with COVID-19, as much as age, comorbidity, and myocardial damage determined by elevated cTnl are.
\end{abstract}

\section{INTRODUCTION}

The infection caused by SARS-CoV-2 has caused a global pandemic with colossal consequences. ${ }^{1}$ Many patients are known to remain asymptomatic or display minor symptoms after becoming infected, but others may require emergency care and hospitalization. ${ }^{2}$ This group of hospitalized patients is sometimes large, and in-hospital mortality is high. ${ }^{3}$

Mortality has been described as being related to several cardiovascular risk factors, including hypertension, diabetes, obesity, and patient comorbidity. ${ }^{4,5}$ It is also known that several biomarkers have prognostic implications, and especially, the presence of myocardial damage detected by the elevation of troponins is crucial in this disease. ${ }^{6}$ It has been described in the literature that the viral load detected in pharyngeal samples, whose detection allows the diagnosis of the infection, could be a useful prognostic marker in hospitalized patients. ${ }^{7-12}$ However, data available on the effects of viral load are controversial, and in most of the published articles, authors have not performed a statistical analysis adjusted for confounding variables. Our work, therefore, aims to analyze the impact of viral load on in-hospital mortality in patients with COVID-19, concerning other well-identified prognostic factors in this entity.

\section{METHODS}

The study, setting, design, and eligibility criteria. No statistical methods were used to predetermine sample size. This is a retrospective observational cohort study, including reports of all patients with confirmed SARS-CoV-2 infections in a university hospital seen between March 16 and May 15, 2020. Patients were not randomized, and investigators were

*Address correspondence to Alfredo Bardají, Cardiology Service, Tarragona Joan XXIII University Hospital, Rovira Virgili University, IISPV, Calle Dr Mallafré Guash 4, Tarragona 43005, Spain. E-mail: abardaji.hj23.ics@gencat.cat not blinded to outcome assessment. The vast majority of patients were first seen in the emergency service, and only those exhibiting extremely severe symptoms were admitted directly to the intensive care unit (ICU).

The patients' identification was made according to the database of determinations of the PCR test for SARS-CoV-2 in our clinical laboratory. The real-time PCR (RT-PCR) reaction was carried out in the CFX96 Touch System thermal cycler (Bio-Rad Laboratories Inc., Hercules, CA) with a commercial kit aimed at amplifying regions of the $\mathrm{E}, \mathrm{N}$, and RdRP genes (Allplex ${ }^{\mathrm{TM}}$ 2019-nCoV Assay, Seegene Inc., Seoul, South Korea). Patients were classified as positive when the $\mathrm{E}$ gene (screening gene) had a cycle threshold $(\mathrm{Ct}) \leq 35$ or a Ct $>35$, with $\mathrm{Ct}<40$ for the confirmatory genes $\mathrm{N}$ and RdRP. Cycle threshold is defined as the amplification cycle's value in which the fluorescence intensity exceeds the threshold, defined as background noise. The $\mathrm{Ct}$ value is inversely proportional to the number of copies of the target analyzed. Cardiac troponin I (cTnl) determinations were carried out with the immunoassay technique (high sensitivity Troponin I from Siemens, Advia Centaur $^{\circledR}$, Munich, Germany). The reference limit for cTnl positivity was $>47 \mathrm{ng} / \mathrm{L}$ (corresponding to the 99th percentile value with total analytical imprecision, expressed by the coefficient of variation, $<10 \%$ ).

In this study, we present a collection of demographic data, cardiovascular risk factors, the reason for emergency care, clinical variables, laboratory tests, electrocardiograms, and imaging techniques (chest X-ray). In patients with several cTnl determinations, the highest value was considered. The Charlson Index $(\mathrm{Cl})$ score was calculated in all patients. ${ }^{13}$ In hospitalized patients, the need for admission to the ICU and the number of days spent being hospitalized in this unit, as well as the need for mechanical ventilation, were analyzed. The primary outcome variable was in-hospital mortality.

Statistical analysis plan. Categorical variables are presented in numbers and percentages, and continuous variables are presented with median and interquartile ranges. For 
comparisons between categorical variables, the chi-square test or Fisher's exact test was used as appropriate, whereas the Mann-Whitney $U$-test was used when comparing continuous variables. The total sample was subdivided into two groups based on the Ct value. A Ct value exceeding 30 was considered to represent a low virus load. ${ }^{11} \mathrm{~A}$ binary logistic regression analysis was performed to establish the association between $\mathrm{Ct}$ and hospital mortality. To avoid over-fitting, this analysis was then adjusted in a multivariate model only for the following variables: age, gender, $\mathrm{Cl}$, and elevated $\mathrm{cTnl}$. The calibration of the model was analyzed with the HosmerLemeshow tests. All statistical calculations were performed using the SPSS version 22 statistical program, and a statistically significant difference was considered if $P<0.05$.

This study is included in a broader research project on myocardial damage detected in patients seen in the emergency department and has the approval of the local Ethics Committee (Ref. CEIM: 195/2020). All patients seen in the emergency department with suspected COVID have a baseline determination of troponin and are therefore included in the general project for myocardial damage. This study is exempt from obtaining signed consent from the patients.

\section{RESULTS}

From an initial sample of 467 patients with suspected COVID-19, 163 were included because of confirmation of the disease and available Ct (Figure 1), with a median age (interquartile range) of 67 (53-78) years. Of the total, 96 (58.9\%) had $\mathrm{Ct}<30$ (high viral load) and 67 (41.1\%) patients had $\mathrm{Ct} \geq 30$ (low viral load).

There were no differences regarding gender, cardiovascular risk factors, and comorbidities between patients with low viral loads and patients with high viral loads, with the exception of chronic lung disease, which was more common in patients with high viral loads (Table 1). There were no differences in symptoms, vital signs, electrocardiograms, or radiological findings between the two groups. There were also no differences in both groups' laboratory tests except for the maximum cTnl, which showed a more significant elevation in the group with high viral load, the difference being statistically significant (Table 2). There were no differences in the need for hospital admission, admission to the ICU, or the need for mechanical ventilation in clinical management (Table 3).
In-hospital mortality was higher in patients with high viral loads than in those with low viral loads (24\% versus $10.4 \%, P=$ $0.029)$ (Figure 2). High viral loads were associated with inhospital mortality in the binary logistic regression analysis (OR: 2.701, 95\% Cl: 1.084-6.725, $P=0.033$ ). However, in an analysis adjusted for age, gender, $\mathrm{Cl}$, and elevated cTnl, only age, $\mathrm{Cl}$, and elevated $\mathrm{cTnl}$ remained in the model (Table 4).

\section{DISCUSSION}

This study shows that in patients admitted to a hospital with a diagnosis of SARS-CoV-2 infection by PCR of the nasopharyngeal exudate, high viral loads (considered at $\mathrm{Ct}<30$ ) are associated (in an unadjusted statistical model) with higher in-hospital mortality. However, when the model is adjusted for the variables that in other studies have shown a strong association with in-hospital mortality, such as age, comorbidity, and myocardial damage determined by the elevation of cTnl, the viral load did not have an independent association with inhospital mortality.

COVID-19 has a broad clinical spectrum, and cardiovascular mortality and complications are concentrated in patients who develop a systemic condition, almost always preceded by bilateral pneumonia that progresses unfavorably. To date, numerous publications have shown that age, male gender, the existence of comorbidities, and cardiovascular risk factors are risk factors for increased mortality in SARS-CoV-2 infection. ${ }^{14-16}$ Likewise, other biochemical parameters play a critical role in severity stratification and prognosis. ${ }^{17,18}$

Nowadays, the diagnosis of SARS-CoV-2 is usually carried out by qualitative RT-PCR as is performed for the viral diagnosis of acute respiratory infections. ${ }^{19}$ The $\mathrm{Ct}$ value refers to the number of cycles in an RT-PCR assay necessary to amplify the RNA and reach a detectable level, considering that the sample is positive if its value oscillates between 0 and 40 . Thus, samples with a high viral load have a low $\mathrm{Ct}$ value, and those with a low viral load have a higher Ct value (needing more amplification cycles). ${ }^{19}$ Previous publications on the 2002 SARS-CoV epidemic of SARS showed that a high viral load was related to more significant morbidity and mortality in the infective process. ${ }^{20}$ Therefore, our work hypothesizes whether or not the detection of the SARS-CoV-2 viral load could be used as a tool to estimate the prognosis of the disease.

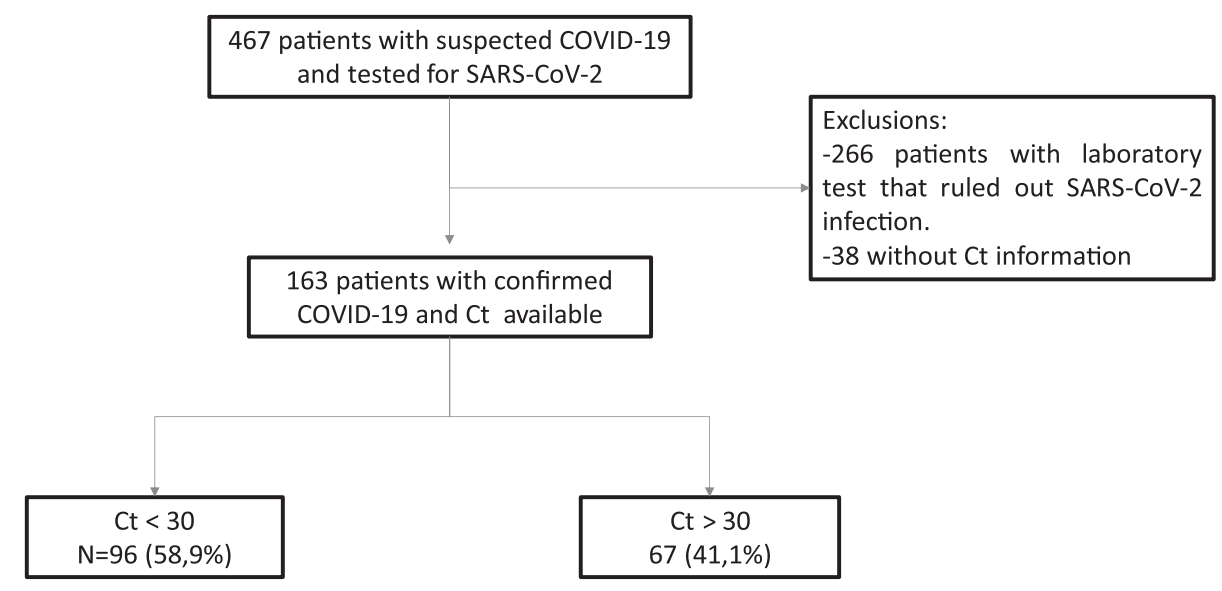

FIGURE 1. Patient flowchart. 
TABLE 1

Demographic variables, risk factors, and comorbidity in the groups analyzed

\begin{tabular}{|c|c|c|c|c|}
\hline & Total $(N=163)$ & High viral load, $\mathrm{Ct}<30(N=96)$ & Low viral load, $\mathrm{Ct}=>30(N=67)$ & $P$-value \\
\hline \multicolumn{5}{|l|}{ Demographic variables } \\
\hline Age (years) & $67(53-78)$ & $74(59.5-81.5)$ & $67.5(53.7-77)$ & 0.277 \\
\hline Male gender & 99 (60.7) & $59(61.5)$ & $40(59.7)$ & 0.821 \\
\hline \multicolumn{5}{|c|}{ Cardiovascular risk factors and comorbidity, $n(\%)$} \\
\hline Arterial hypertension & 79 (48.5) & $46(51)$ & $30(44.8)$ & 0.431 \\
\hline Diabetes mellitus & $42(25.8)$ & $26(27.1)$ & $16(23.9)$ & 0.064 \\
\hline Dyslipidemia & $46(28.2)$ & $29(30.2)$ & $17(25.4)$ & 0.5 \\
\hline Smoking & $36(21.1)$ & $24(25)$ & $12(17.9)$ & 0.283 \\
\hline \multicolumn{5}{|l|}{ Cardiovascular history, $n$ (\%) } \\
\hline Myocardial infarction & $15(9.2)$ & $12(12.5)$ & $3(4.5)$ & 0.081 \\
\hline Heart failure & $13(8)$ & $9(9.4)$ & $4(6)$ & 0.43 \\
\hline Peripheral artery disease & $9(5.5)$ & $8(8.3)$ & $1(1.5)$ & 0.06 \\
\hline Cerebrovascular disease & $12(7.4)$ & $7(7.3)$ & $5(7.5)$ & 0.967 \\
\hline Chronic kidney disease & $17(10.4)$ & $12(12.5)$ & $5(7.5)$ & 0.301 \\
\hline Chronic lung disease & $26(16)$ & 19 (19.8) & 7 (10.4) & 0.019 \\
\hline Dementia & $15(9.2)$ & $8(8.3)$ & 7 (10.4) & 0.646 \\
\hline Neoplasms & $18(11)$ & $13(13.5)$ & $5(7.5)$ & 0.223 \\
\hline Charlson Index & $1(0-3)$ & $2(0-3)$ & $1(0-2)$ & 0.064 \\
\hline
\end{tabular}

Liu et al. ${ }^{10}$ found that in a cohort of 76 patients, the mean viral load in severe patients was up to 60 times higher than that in mild cases. A systematic review of 18 studies carried out in the Chinese population concludes that low Ct values are significantly correlated with mortality, disease progression, and more remarkable alteration of at least one serum biomarker, including an increase in lactate dehydrogenase, a decrease of lymphocytes, and an increase in cTnl values. ${ }^{21,22}$ It is possible that in patients with extreme baseline severity, the viral load does affect prognosis. Hospital mortality in the Pujadas series was $32 \%,{ }^{23}$ and in the Westblade series was $25 \%,{ }^{24}$ thus, significantly higher than our study $(18.4 \%)$. However, another study carried out in Italy, with a cohort of more than 5,000 patients, did not reveal any significant

TABLE 2

Main symptoms, vital signs on admission, examinations performed, and laboratory tests at the time of admission among the groups analyzed

\begin{tabular}{|c|c|c|c|c|}
\hline & Total $(N=163)$ & High viral load, $\mathrm{Ct}<30(N=96)$ & Low viral load, $\mathrm{Ct}=>30(N=67)$ & $P$-value \\
\hline \multicolumn{5}{|l|}{ Symptoms, $n$ (\%) } \\
\hline Dyspnea & $96(58.9)$ & $56(58.3)$ & $40(59.7)$ & 0.861 \\
\hline Fever & 123 (76.9) & 77 (80.2) & $46(71.9)$ & 0.221 \\
\hline Cough & $87(54.4)$ & $52(54.2)$ & $35(54.7)$ & 0.948 \\
\hline Myalgia & $10(6.3)$ & $5(5.3)$ & $5(7.8)$ & 0.516 \\
\hline Diarrhea & $25(15.6)$ & $15(15.6)$ & $10(15.6)$ & 1 \\
\hline Chest pain & $14(8.6)$ & $6(6.3)$ & $8(11.9)$ & 0.202 \\
\hline Other symptoms & 79 (48.5) & $50(52.1)$ & $29(43.3)$ & 0.269 \\
\hline Symptom time (days) & $5(2-8)$ & $5.5(2-8)$ & $5(1.5-9)$ & 0.496 \\
\hline \multicolumn{5}{|l|}{ Vital signs } \\
\hline Heart rate (bpm) & $86(73-102)$ & $82(73-93)$ & $84.5(70-100)$ & 0.566 \\
\hline Systolic blood pressure $(\mathrm{mmHg})$ & $124(111-138)$ & $127(109-139)$ & $125(110-139)$ & 0.565 \\
\hline Oxygen saturation (\%) & $96(91-99)$ & $95(90-97)$ & $96(90-98)$ & 0.229 \\
\hline \multicolumn{5}{|l|}{ Electrocardiogram, $n$ (\%) } \\
\hline Atrial fibrillation & $17(11.3)$ & $14(15.4)$ & $3(5)$ & 0.48 \\
\hline $\begin{array}{l}\text { Left bundle branch block or right bundle } \\
\text { branch block }\end{array}$ & $6(4)$ & $2(2.2)$ & $4(6.7)$ & 0.169 \\
\hline \multicolumn{5}{|l|}{ Radiological findings, $n(\%)$} \\
\hline Consolidation & $34(20.9)$ & $16(19.8)$ & $15(22.4)$ & 0.688 \\
\hline Frosted glass & $16(9.8)$ & $12(12.5)$ & $4(6)$ & 0.168 \\
\hline Bilateral infiltrators & $106(65.4)$ & $62(65.3)$ & $44(65.7)$ & 0.957 \\
\hline \multicolumn{5}{|l|}{ Laboratory tests } \\
\hline Blood glucose (mg/dL) & $105(89-136)$ & $106(89-146)$ & $104(88-136)$ & 0.87 \\
\hline $\begin{array}{l}\text { Glomerular filtration rate }(\mathrm{mL} / \text { minute } \\
\left.\text { per } 1.73 \mathrm{~m}^{2}\right)\end{array}$ & $93(63-113)$ & $78(48-110)$ & $93(74-118)$ & 0.191 \\
\hline Hemoglobin $(\mathrm{g} / \mathrm{dL})$ & $12.5(11.2-13.9)$ & $11.8(10.6-13.0)$ & $12,0(11.5-13.9)$ & 0.147 \\
\hline 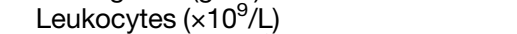 & $6.450(4.710-8.910)$ & $6.680(4.530-9.555)$ & 7.775 (5.557-9.042) & 0.815 \\
\hline Lymphocytes $\left(\times 10^{9} / \mathrm{L}\right)$ & $0.8(0.4-0.1)$ & $0.6(0.3-0.1)$ & $0.8(0.2-0.1)$ & 0.542 \\
\hline Platelets $\left(\times 10^{9} / \mathrm{L}\right)$ & $212(157-282)$ & $190(152-264)$ & $241(158-328)$ & 0.068 \\
\hline $\mathrm{D}$-dimer (ng/mL) & $714(431-1,679)$ & $1,102(530-2018)$ & $965(445-1947)$ & 0.886 \\
\hline Lactate dehydrogenase $(\mathrm{U} / \mathrm{L})$ & $278(220-387)$ & $308(235-397)$ & $269(231-412)$ & 0.833 \\
\hline C-reactive protein (mg/dL) & $9(3-16)$ & $9(4-17)$ & $8.5(3-18)$ & 0.922 \\
\hline cTnl maximum (ng/L) & $13(4-35)$ & $24(9.5-58.5)$ & $8.5(3-22.5)$ & 0.007 \\
\hline Elevated cTnl & $29(17.8)$ & $20(20.8)$ & $9(13.4)$ & 0.224 \\
\hline
\end{tabular}

$\mathrm{Ct}=$ cycle threshold; $\mathrm{cTnl}=$ cardiac troponin $\mathrm{I}$. 
TABLE 3

Data on hospital admission, treatments administered, and mortality among the groups analyzed

\begin{tabular}{|c|c|c|c|c|}
\hline & Total $(N=163)$ & High viral load, $\mathrm{Ct}<30(N=96)$ & Low viral load, $\mathrm{Ct}=>30(N=67)$ & $P$-value \\
\hline \multicolumn{5}{|l|}{ Clinical management, $n$ (\%) } \\
\hline Admission to hospital & $141(86.5)$ & $85(88.5)$ & $56(83.6)$ & 0.362 \\
\hline Admission to ICU & $31(19)$ & $15(15.6)$ & $16(23.9)$ & 0.186 \\
\hline Days in ICU & $10(0-33)$ & $10.5(0-35)$ & $7(0-25)$ & 0.654 \\
\hline Mechanic ventilation & $26(16)$ & $13(13.5)$ & $13(19.4)$ & 0.315 \\
\hline Acute myocardial infarction type 2 & $15(9.2)$ & $6(6.3)$ & 9 (13.4) & 0.199 \\
\hline \multicolumn{5}{|l|}{ Treatment, $n(\%)$} \\
\hline Antibiotics* & $123(75.9)$ & 74 (77.9) & $49(73.1)$ & 0.485 \\
\hline Hydroxychloroquine & $104(64.6)$ & $58(61.7)$ & 46 (68.7) & 0.363 \\
\hline Lopinavir/ritonavir & $80(50)$ & $47(50)$ & $33(50)$ & 1 \\
\hline Azithromycin & $57(35.8)$ & $26(28.3)$ & 31 (46.3) & 0.019 \\
\hline Corticosteroids & $14(8.7)$ & $11(11.7)$ & $3(4.5)$ & 0.109 \\
\hline $\begin{array}{l}\text { Angiotensin-converting enzyme } \\
\text { inhibitor or angiotensin receptor } \\
\text { blocker }\end{array}$ & $20(15.2)$ & $11(14.5)$ & $9(16.1)$ & 0.808 \\
\hline \multicolumn{5}{|l|}{ Mortality, $n(\%)$} \\
\hline In-hospital mortality & $30(18.4)$ & $23(24)$ & $7(10.4)$ & 0.029 \\
\hline
\end{tabular}

differences between viral load and disease severity. ${ }^{25}$ Another recent study, which included 205 patients and that performed a multivariate analysis, also found no differences in hospitalization length, the need for oxygen therapy, or mortality rates during follow-up. ${ }^{9}$

Viral load levels are known to be higher in the upper respiratory tract (nasopharynx and oropharynx) than in the lower respiratory tract, suggesting that the high replicability of the virus occurs in the nose and throat. ${ }^{26}$ In most patients with symptomatic COVID-19 infection, the viral RNA in the nasopharyngeal smear measured by Ct becomes detectable on the first day of symptoms and reaches its maximum peak within 1 week of symptom onset. PCR positivity may persist beyond three weeks after disease onset when milder cases would have a negative result, which suggests that a positive PCR result reflects only the detection of viral RNA and does not necessarily indicate the presence of a viable virus. ${ }^{27}$ These findings are consistent with other studies that conclude that

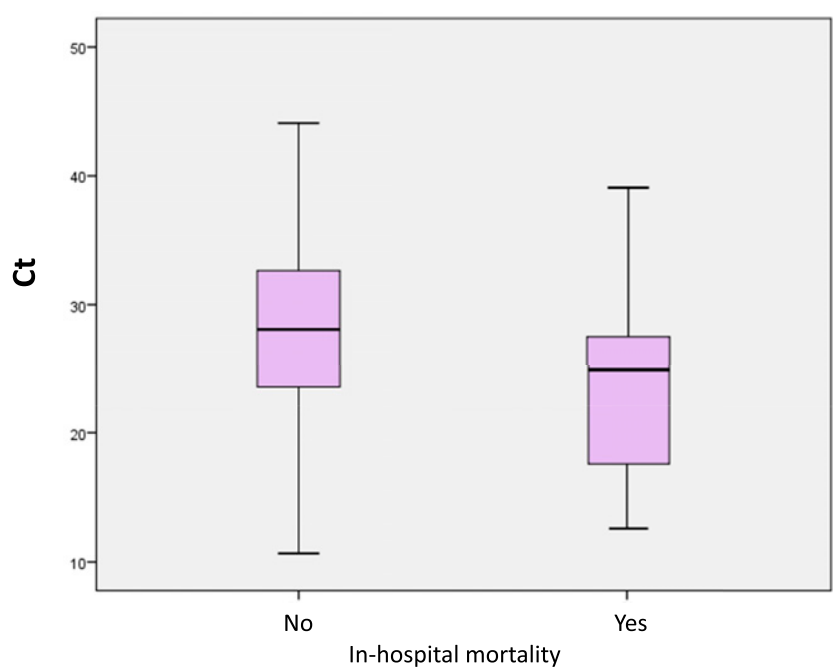

FiguRE 2. Box plot diagram of viral load cycle threshold (Ct) as a function of in-hospital mortality. This figure appears in color at www.ajtmh.org. before symptoms appear, the beginning of the infection is when the virus is reproducing the most, at least in the upper respiratory tract. ${ }^{9}$ This is not associated with either the duration of the symptoms or their severity. Other work published by Lavezzo et al. ${ }^{28}$ has shown that asymptomatic patients can spread COVID-19 in a very similar way to those that have symptoms. In our work, the probability of death in the univariate analysis was higher when the patients were older, with a higher $\mathrm{Cl}$ score, elevated $\mathrm{cTnl}$, and low Ct value results, similar to the data published by Zheng et al. ${ }^{8}$ In our sample, the association between mortality and Ct values was analyzed using multivariate analysis, in which viral load was no longer a predictor of mortality.

In general, SARS-CoV-2 infection has low mortality in most cases, as shown in the literature, but $10-15 \%$ of those infected suffer from the pulmonary disease, with different degrees of systemic disease leading to higher mortality, ${ }^{29,30}$ as has been registered in our study. When we analyzed our data, we want to note that there was a lack of knowledge about the treatments to be applied in patients with COVID-19. For example, many patients received (cardiotoxic) medications (that, in the end, do not improve outcomes), and only a few received steroids (that, in the end, improved outcomes). Our data seem to indicate that the viral load value present in respiratory samples is not the determining element in the prognosis of the COVID-19 disease, as much as age, the underlying pathologies that the patients present, and myocardial injury. Besides, the series of mechanisms triggered by the excessive activation of the immune system, which generates a cytosine storm and a pro-inflammatory and prothrombotic state, leads to higher mortality. ${ }^{31}$

Our study has several limitations. It was a retrospective observational study carried out in a single center with a relatively small sample size. The viral load determination was measured at the time of admission and was only obtained from respiratory samples from the upper tract. For the identification of patients, the PCR for SARS-CoV-2 was used, and although it is the method commonly used in the health field, it presents some complexity; it can have false positives and false negatives in the results. We did not have information on markers for oxygenation, like S/F (transcutaneous saturation/inspired oxygen fraction) ratio, or ROX index (ratio of oxygen saturation as 
TABLE 4

Predictors of in-hospital mortality by binary logistic regression

\begin{tabular}{|c|c|c|c|c|}
\hline & \multicolumn{2}{|c|}{ Univariate analysis } & \multicolumn{2}{|c|}{ Multivariate analysis } \\
\hline & OR $(95 \% \mathrm{Cl})$ & $P$-value & OR $(95 \% \mathrm{Cl})$ & $P$-value \\
\hline Age & 1.067 (1.032-1.104) & $<0.001$ & $1.044(1.004-1.086)$ & 0.031 \\
\hline Male gender & $1.645(0.701-3.864)$ & 0.253 & - & - \\
\hline Charlson score & 1.711 (1.355-2.160) & $<0.001$ & 1.365 (1.058-1.760) & 0.016 \\
\hline Cardiac troponin I elevated & $8.500(3.439-21.101)$ & $<0.001$ & 4.835 (1.786-13.076) & 0.002 \\
\hline Cycle threshold $<30$ & $2.701(1.084-6.725)$ & 0.033 & - & - \\
\hline
\end{tabular}

measured by pulse oximetry/ $/ \mathrm{FIO}_{2}$ to respiratory rate). Another limitation was not having information on the viral load in asymptomatic or mildly symptomatic patients who did not require a PCR test. Furthermore, it is possible that because of the nature of a retrospective study, we have not collected other confounding variables, which could have influenced the final results.

In conclusion, the determination of the viral load measured by the Ct value in patients with confirmed COVID-19 infection did not allow the risk of mortality to be stratified quickly and early because some other clinical factors and biomarkers do have a strong association with mortality. Higher viral load does not appear to predict a worse prognosis for the disease, but it can be used as an epidemiological marker of infectivity in mildly asymptomatic and asymptomatic outpatients.

Received October 4, 2020. Accepted for publication December 8, 2020.

Published online December 23, 2020.

Acknowledgment: The American Society of Tropical Medicine and Hygiene has waived the Open Access fee for this article due to the ongoing COVID-19 pandemic.

Financial support: This project has been carried out, in part, with the help of a FIS grant on Health Research Projects, Strategic Action in Health 2017-2020, PI19/00705, and by a the grant COVID-196_17 (to Francesc Vidal), Direcció General de Recerca i Innovació en Salut (Departament de Salut) and BIOCAT, Generalitat de Catalunya.

Authors' addresses: Anna Carrasquer, Óscar M. Peiró, Raul SanchezGimenez, Nisha Lal-Trehan, Victor del-Moral-Ronda, Gil Bonet, and Alfredo Bardají, Department of Cardiology, Joan XXIII University Hospital, Pere Virgili Health Research Institute (IISPV), Rovira Virgili University, Tarragona, Spain, E-mails: carrasquer1987@gmail.com, opi220290@gmail.com, raul.sagi@hotmail.com, nishalal593@ gmail.com, moral.ronda@gmail.com, gil.bonet.p@gmail.com, and abardaji.hj23.ics@gencat.cat. Cristina Gutierrez, Isabel Fort-Gallifa, Carla Martin-Grau, and Clara Benavent, Clinical Laboratory, Catalan Institute of Health, Tarragona, Spain, E-mails: cgutierrez.hj23.ics@ gencat.cat, ifgallifa.hj23.ics@gencat.cat, cgmartin.hj23.ics@gencat. cat, and cbenavent.hj23.ics@gencat.cat. Francesc Vidal, Infectious Disease Unit, Department of Internal Medicine, Joan XXIII University Hospital, Pere Virgili Health Research Institute (IISPV), Rovira Virgili University, Tarragona, Spain, E-mail: abardaji.hj23.ics@gencat.cat.

This is an open-access article distributed under the terms of the Creative Commons Attribution (CC-BY) License, which permits unrestricted use, distribution, and reproduction in any medium, provided the original author and source are credited.

\section{REFERENCES}

1. Lai CC, Wang CY, Wang YH, Hsueh SC, Ko WC, Hsueh PR, 2020. Global epidemiology of coronavirus disease 2019 (COVID-19): disease incidence, daily cumulative index, mortality, and their association with country healthcare resources and economic status. Int J Antimicrob Agents 55: 105946.

2. Zhou F et al., 2020. Clinical course and risk factors for mortality of adult inpatients with COVID-19 in Wuhan, China: a retrospective cohort study. Lancet 395: 1054-1062.
3. Chen T et al., 2020. Clinical characteristics of 113 deceased patients with coronavirus disease 2019: retrospective study. BMJ 368: $\mathrm{m} 1091$.

4. Yang J, Zheng Y, Gou X, Pu K, Chen Z, Guo Q, Ji R, Wang H, Wang Y, Zhou Y, 2020. Prevalence of comorbidities and its effects in coronavirus disease 2019 patients: a systematic review and meta-analysis. Int $J$ Infect Dis 94: 91-95.

5. Carrasquer A, Peiró ÓM, Sánchez-giménez R, Lal-trehan N, Bardají A, 2020. Implicaciones pronóstico del Índice de Charlson y daño miocárdico en pacientes COVID-19 atendidos en urgencias. Emergencias (Epub ahead of print).

6. Bardaji A et al., 2020. Prognostic implications of myocardial injury in patients with and without COVID-19 infection treated in a university hospital. Rev Esp Cardiol 74: 24-32.

7. Zhou R, Li F, Chen F, Liu H, Zheng J, Lei C, Wu X, 2020. Viral dynamics in asymptomatic patients with COVID-19. Int $J$ Infect Dis 96: 288-290.

8. Zheng $S$ et al., 2020. Viral load dynamics and disease severity in patients infected with SARS-CoV-2 in Zhejiang province, China, January-March 2020: retrospective cohort study. BMJ 369: $\mathrm{m} 1443$.

9. Argyropoulos KV et al., 2020. Association of initial viral load in severe acute respiratory syndrome coronavirus 2 (SARS-CoV2) patients with outcome and symptoms. Am J Pathol 190: 1881-1887.

10. Liu Y, Yan LM, Wan L, Xiang TX, Le A, Liu JM, Peiris M, Poon LLM, Zhang W, 2020. Viral dynamics in mild and severe cases of COVID-19. Lancet Infect Dis 20: 656-657.

11. Magleby R, Westblade LF, Trzebucki A, Simon MS, Rajan M, Park J, Goyal P, Safford MM, Satlin MJ, 2020. Impact of SARS-CoV-2 viral load on risk of intubation and mortality among hospitalized patients with Coronavirus disease 2019. Clin Infect Dis 30: ciaa851.

12. Faíco-Filho KS, Passarelli VC, Bellei N, 2020 Is higher viral load in SARS-CoV-2 associated with death? Am J Trop Med Hyg 103: 2019-2021.

13. Charlson ME, Pompei $P$, Ales KL, MacKenzie CR, 1987. A new method of classifying prognostic comorbidity in longitudinal studies: development and validation. J Chronic Dis 40: 373-383.

14. Wang $D$ et al., 2020. Clinical characteristics of 138 hospitalized patients with 2019 novel Coronavirus-infected pneumonia in Wuhan, China. JAMA 323: 1061-1069.

15. Lian $\mathrm{J}$ et al., 2020. Epidemiological, clinical, and virological characteristics of 465 hospitalized cases of coronavirus disease 2019 (COVID-19) from Zhejiang province in China. Influenza Other Respi Viruses 14: 564-574.

16. Ortiz-Prado E et al., 2020. Clinical, molecular, and epidemiological characterization of the SARS-CoV-2 virus and the coronavirus disease 2019 (COVID-19), a comprehensive literature review. Diagn Microbiol Infect Dis 98: 115094.

17. Pascual Gómez NF, Monge Lobo I, Granero Cremades I, Figuerola Tejerina A, Ramasco Rueda F, von Wernitz Teleki A, Arrabal Campos FM, Sanz de Benito MA, 2020. Potential biomarkers predictors of mortality in COVID-19 patients in the emergency department. Rev Esp Quimioter 33: 267-273.

18. Uribarri A et al., 2020. Impact of renal function on admission in COVID-19 patients: an analysis of the international HOPE COVID-19 (Health Outcome Predictive Evaluation for COVID 19) Registry. J Nephrol 33: 737-745.

19. Reina J, Morales C, Busquets M, Norte C, 2018. Usefulness of Ct value in acute respiratory infections caused by respiratory syncytial virus $A$ and $B$ and influenza virus $A(H 1 N 1)$ pdm09, $A$ (H3N2) and B. Enferm Infecc Microbiol Clin 36: 332-335. 
20. Chu CM et al., 2004. Initial viral load and the outcomes of SARS. $C$ Can Med Assoc 171: 1349-1352.

21. Rao SN, Manissero D, Steele VR, Pareja J, 2020. A systematic review of the clinical utility of cycle threshold values in the context of COVID-19. Infect Dis Ther 9: 573-586.

22. Martín-Grau C, Benavent-Bofill C, Picó-Plana E, Recio-Comí G, Terrón-Puig M, Bastón-Paz N, Sans-Mateu MT, GutiérrezFornés C, 2020. Use of predictive tools in the management of COVID-19 patients: a key role of clinical laboratories. Adv Lab Med, 20200059. doi: 10.1515/almed-2020-0059. (Epug ahead of print).

23. Pujadas E, Chaudhry F, McBride R, Richter F, Zhao S, Wajnberg A, Nadkarni G, Glicksberg BS, Houldsworth J, Cordon-Cardo C, 2020. SARS-CoV-2 viral load predicts COVID-19 mortality. Lancet Respir Med 8: e70.

24. Westblade LF et al., 2020. SARS-CoV-2 viral load predicts mortality in patients with and without cancer who are hospitalized with COVID-19. Cancer Cell 38: 661-671.
25. Micheli V et al., 2020. Geographical reconstruction of the SARSCoV-2 outbreak in Lombardy (Italy) during the early phase. J Med Virol. doi: 10.1002/jmv.26447.

26. Wölfel $R$ et al., 2020. Virological assessment of hospitalized patients with COVID-2019. Nature 581: 465-469.

27. Sethuraman N, Jeremiah SS, Ryo A, 2020. Interpreting diagnostic tests for SARS-CoV-2. JAMA 323: 2249-2251.

28. Lavezzo E et al., 2020. Suppression of a SARS-CoV-2 outbreak in the Italian municipality of Vo'. Nature 584: 425-429.

29. Feng $Y$ et al., 2020. COVID-19 with different severities: a multicenter study of clinical features. Am J Respir Crit Care Med 201: 1380-1388.

30. Guan WJ et al., 2020. Clinical characteristics of Coronavirus disease 2019 in China. N Engl J Med 382: 1708-1720.

31. Guzik TJ et al., 2020. COVID-19 and the cardiovascular system: implications for risk assessment, diagnosis, and treatment options. Cardiovasc Res 116: 1666-1687. 